\title{
PROCESSO DE COMERCIALIZAÇÃO DE INOVAÇÕES: UMA ANÁLISE DA TRAJETÓRIA DE UMA PEQUENA EMPRESA DE BASE TECNOLÓGICA
}

Rodrigo Lacerda Sales ${ }^{1}$

Francisco José De Castro Moura Duarte ${ }^{2}$

Anne-Marie Maculan ${ }^{3}$

${ }^{1}$ Centro Federal de Educação Tecnológica de Minas Gerais

${ }^{2}$ Programa de Engenharia de Produção / Coppe / Universidade Federal do Rio de Janeiro

${ }^{3}$ Universidade Federal do Rio de Janeiro 


\section{PROCESSO DE COMERCIALIZAÇÃO DE INOVAÇÕES: UMA ANÁLISE DA TRAJETÓRIA DE UMA PEQUENA EMPRESA DE BASE TECNOLÓGICA}

\section{Resumo:}

O objetivo geral deste artigo é caracterizar o processo de comercialização de uma pequena empresa de base tecnológica - PEBT graduada em uma incubadora brasileira. Mais especificamente pretende-se: (1) identificar quais dificuldades essa empresa enfrentou ao longo desse processo, (2) identificar quais foram as soluções aplicadas por ela para introduzir suas inovações no mercado e (3) identificar se o período de incubação teve alguma influência na comercialização. A pesquisa foi do tipo exploratório-descritivo, com uma abordagem metodológica qualitativa. A principal dificuldade enfrentada pela PEBT está na base de competências em gestão e comercialização por parte dos empreendedores, o que pode ser explicado pelo fato da empresa ter sido criada por empreendedores técnicos (empreendedor acadêmico) com uma forte orientação tecnológica e fraca orientação mercadológica e empresarial.

Palavras-chave: pequenas empresas de base tecnológica. processo de comercialização. inovação.

\section{Introdução}

No atual ambiente de negócios, a competitividade está fortemente dependente da capacidade das empresas para criar e explorar efetivamente suas inovações. Segundo Tidd e Bessant (2015), a inovação é entendida não como um evento isolado, mas sim como um processo, portanto, precisa ser gerenciada como tal. Para esses autores, esses processos (que são complexos e dinâmicos) requerem uma gestão que envolve em suas várias áreas do conhecimento, um conjunto de comportamentos organizacionais que possam promover ano capacidade de informar, a habilidade de organizar e gerenciar o processo, buscando a integração desses processos com a tecnologia e o mercado.

Talvez a gestão da inovação em grandes empresas seja mais estruturada em função do porte, dos recursos e estruturas disponíveis para tal. As empresas de base tecnológica de pequeno porte - PEBTs diferem das grandes empresas em muitos aspectos relacionados com a inovação. Essas empresas geralmente têm estratégias de entrada no mercado relativamente limitadas, poucos recursos financeiros para desenvolvê-las e carecem de habilidades em gestão e formulação de estratégia de comercialização (HANG DO, 2014; PELIKKA e MALINEN, 2014 e 2015; PELLIKKA, 2014; PELLIKKA e PELLIKKA, 2011; FORSMAN, 2011; LIAO 
e RICE, 2010; de JONG e MARSILI, 2006; FREEL, 2005; WONGLIMPIYARAT e YUBERK, 2005; IACONO e NAGANO, 2014).

Além disso, a estrutura e os processos de pequenas empresas são relativamente informais, e, em geral, os objetivos de negócios e as estratégias relacionadas não são muito claros, devido à limitada experiência dos dirigentes em gestão e implementação de atividades destinadas a comercializar os produtos (PELLIKKA e PELLIKKA, 2011; PELIKKA e MALINEN, 2014 e 2015; HANG DO, 2014).

Visando minimizar essas limitações, as PEBTs buscam apoio de agentes de inovação e universidades e geralmente passam por um processo de incubação. De acordo com Andrade Júnior (2014), o Brasil tem estimulado as PEBTs por meio da criação de incubadoras que proporcionam a esses empreendimentos vários mecanismos de apoio, como infraestrutura física, operacional e de assessoria. Para ele, as incubadoras tecnológicas constituem uma alternativa estratégica que impulsiona o desenvolvimento econômico das regiões onde estão inseridas, aumentando as oportunidades de emprego, a geração de renda e diversificando a oferta de bens e serviços por meio de condições favoráveis ao avanço da tecnologia (ANDRADE JÚNIOR, 2012). Estudos da ANPROTEC (2012 e 2015) também indicam o crescimento desse movimento das incubadoras e das PEBTs que passam pelo processo de incubação.

A literatura pesquisada neste trabalho indica que a capacidade de comercialização de inovações em PEBTs é umas das principais limitações ao crescimento dessas empresas e, portanto, torna-se importante caracterizar melhor esse processo de comercialização tal como gerenciado pelas PEBTs, bem como as práticas, os problemas e as soluções introduzidas para inserir as inovações no mercado, identificar potenciais compradores ou usuários e atender as demandas identificadas.

Nesse contexto, é possível apontar para as seguintes questões de pesquisa: (1) Como é o processo de comercialização de inovações de uma PEBT graduada? (2) Quais as dificuldades a empresa enfrenta nesse processo? (3) Como supera essas dificuldades para introduzir suas inovações no mercado? 4) O período de incubação tem alguma influência na comercialização?

O objetivo geral deste artigo é caracterizar o processo de comercialização de uma pequena empresa de base tecnológica - PEBT graduada em uma incubadora brasileira. Mais especificamente pretende-se: (1) identificar quais dificuldades essa empresa enfrentou ao longo desse processo, (2) identificar quais foram as soluções aplicadas por ela para introduzir suas inovações no mercado e (3) identificar se o período de incubação teve alguma influência na comercialização

Esta pesquisa delimitará seu foco de estudo em uma PEBT graduada na Incubadora de Base Tecnológica da Universidade Federal de Viçosa - IBT/UFV. Tal delimitação se justifica por dois motivos: (1) Natureza das PEBTs: as incubadoras de base tecnológica geralmente têm como premissas em seus editais de seleção que somente poderão participar dos processos seletivos empresas com projetos que possuam características inovadoras com possibilidades de ter viabilidade econômica, financeira e comercial, (2) Fase de maturidade do negócio: empresas que passaram por um processo de incubação, se graduaram e se encontram no mercado há mais de cinco anos, já podem ter adquirido experiência e know how, em relação às suas práticas de comercialização e superado as dificuldades em relação á comercialização de suas inovações.

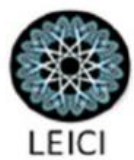


Para identificar se a PEBT realmente introduziu no mercado produtos ou serviços inovadores, foram considerados na seleção do caso três elementos, são eles: (1) Propriedade Intelectual (especificamente patentes e registro de software); (2) Investimentos em P\&D e (3) Captação de recursos em Agências de Fomento para o desenvolvimento das tecnologias introduzidas no mercado.

Além dessa introdução, este artigo apresenta na próxima sessão o referencial teórico, seguido pela metodologia, resultados/discussão, considerações finais e as referências bibliográficas utilizadas.

\section{Referencial Teórico}

\subsection{Comercialização de Inovaç̃̃es}

Ao realizarem uma revisão de literatura sobre áreas-chave de pesquisa com foco em gestão da inovação, Adams, Bessant e Phelps (2006) identificaram que existem lacunas significativas, particularmente no campo da comercialização. Os autores destacam sete áreas sobre a medição da gestão da inovação: 1) inputs - pessoas, recursos físicos e financeiros, ferramentas; 2) gestão do conhecimento - geração de ideias, repositório de conhecimentos, fluxos de informação; 3) estratégia de inovação - orientação estratégica, liderança estratégica; 4) organização e cultura - cultura, estrutura; 5) gestão de portfólio - equilíbrio risco / retorno, uso de ferramentas de otimização; 6) gerenciamento de projetos - eficiência do projeto, ferramentas, comunicações, colaboração; e 6) comercialização - pesquisa de mercado, testes de mercado, marketing e vendas.

Para esses autores, o processo de comercialização está relacionado às capacidades de marketing da empresa, tais como pesquisa de mercado, promoção, planejamento e monitoramento de mercado a fim de lançar os produtos ou serviços.

Nesta direção, Moore (2002) enfatizou o significado da orientação para o mercado e as dificuldades das empresa para identificar o segmento de mercado inicial e a abordagem que será adotada na comercialização de inovações.

A comercialização é o resultado final do longo processo de uma estratégia de inovação, cujos elementos e complexidade vão se afunilando ao longo da gestão da inovação (MAZZAROL, REBOUD e SOUTAR, 2011).

De acordo com Zahra e Nielsen (2002), a comercialização é o processo através do qual as empresas criam valor econômico por meio da transformação e incorporação de conhecimentos, descobertas e invenções, em produtos e serviços novos ou significativamente melhorados para atender a demandas dos compradores e consumidores no mercado.

A definição de comercialização de inovações de Datta, Red e Jessup (2013) tem três elementos constitutivos: (1) o reconhecimento de um mercado para uma inovação; (2) desenvolvimento e fabricação de um produto e (3) a venda / distribuição do produto.

O primeiro elemento é endereçado através dos temas de fontes de inovação, bem como tipos de inovação e proteção. Os dois últimos são essencialmente abordados através de entrada no mercado, desenvolvimento e implantação. Os autores desmentem a ideia de que a comercialização de inovação é uma construção simples. Argumentam que são várias as definições, conceituações e operacionalizações que surgem dos estudos publicados.

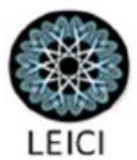




\subsection{Pensando a Comercialização de inovações como um processo}

A comercialização é um elemento do processo de inovação tecnológica, principalmente por causa dos altos riscos, custos e das incertezas que ela implica. Muitas vezes é a fase que acarreta mais problemas de gestão em todo o processo de inovação (COSTA, FONTES e HEITOR, 2004; PELLIKKA e VIRTANEN, 2009 e CHIESA e FRATTINI, 2011).

Ao realizarem uma revisão de literatura sobre áreas-chave de pesquisa com foco em gestão da inovação, Adams, Bessant e Phelps (2006) identificaram que existem lacunas significativas, particularmente no campo da comercialização, dentre elas destacam: (1) inputs (pessoas, recursos físicos e financeiros, ferramentas); (2) gestão do conhecimento (geração de ideias, repositório de conhecimentos, fluxos de informação); (3) estratégia de inovação (orientação estratégica, liderança estratégica); (4) comercialização (pesquisa de mercado, testes de mercado, marketing e vendas). Para esses autores, o processo de comercialização está relacionado às capacidades de marketing da empresa, tais como pesquisa de mercado, promoção, planejamento e monitoramento de mercado a fim de lançar os produtos ou serviços.

Moore (2002) também enfatiza a capacidade de marketing das empresas e o significado da orientação para o mercado, que significa a compreensão do ciclo de vida da adoção de tecnologia. Segundo o autor, somente a partir do entendimento desse ciclo de vida foi possível superar as dificuldades das empresas para identificar o segmento de mercado inicial e a abordagem que será adotada na comercialização de inovações.

A comercialização é o resultado final do longo processo de uma estratégia de inovação, cujos elementos e complexidade vão se afunilando ao longo da gestão da inovação (MAZZAROL, REBOUD e SOUTAR, 2011).

De acordo com Zahra e Nielsen (2002), a comercialização é o processo através do qual as empresas criam valor econômico transformando e incorporando conhecimentos, descobertas e invenções, em produtos e serviços novos ou significativamente melhorados para atender a demandas dos compradores e consumidores no mercado.

Datta, Red e Jessup (2013) consideram que a comercialização de inovações uma atividade empresarial com três elementos constitutivos: (1) o reconhecimento de um mercado para uma inovação; (2) desenvolvimento e fabricação de um produto e (3) a venda / distribuição do produto. O primeiro elemento é endereçado através dos temas de fontes de inovação, bem como tipos de inovação e proteção. Os dois últimos são essencialmente abordados através de entrada no mercado, desenvolvimento e implantação.

Sendo a comercialização de inovações uma atividade empresarial, pensa-la como um processo pode facilitar sua gestão. $O$ termo processo de comercialização se refere a um elemento essencial da gestão da inovação tecnológica, o processo pelo qual os investimentos em pesquisa e desenvolvimento - P \& D se transformam em inovação tecnológica e são efetivamente comercializados (PELLIKKA e LAURONEN, 2007; PELLIKKA e VIRTANEN, 2009; KAJANUS et. al., 2011 e PELLIKKA e MALINEN, 2014 e 2015).

Para Hang Do (2014) a gestão da inovação é amplamente considerada como um fator chave para o crescimento das empresas. No entanto, apesar de numerosos estudos neste campo, existe uma relativa escassez de pesquisas sobre o processo de comercialização em pequenas e

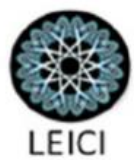


médias empresas. O autor considera que esses empreendimentos são importantes para o desenvolvimento econômico, mas têm recursos limitados à sua disposição para a inovação. Além disso adotam uma abordagem menos sistemática e formalizada e mais intuitiva em matéria de inovação, sem processos formais, contando com conhecimento do mercado local e criatividade. Segundo Hang Do (2014), esta falta de processos formais apresenta uma das razões potenciais que causam alta taxa de falhas na comercialização de inovações.

Nesta direção, Adams, Bessant e Phelps (2006) sugeriram que a fraca prática de gestão da inovação pelas pequenas empresas impõe a elas um desafio em função dos escassos recursos para o processo de comercialização.

Para Pellikka e Lauronen (2007) e Pellikka e Malinen (2015), o processo de comercialização possui cinco fases, iniciando com a Fase de Desenvolvimento da Ideia e terminando com a Fase de Manutenção do Negócio, conforme detalhes apresentados na Figura 1 .

Cabe destacar que, a Fase de Lançamento no Mercado que, segundo Pellikka e Lauronen (2007) e Pellikka e Malinen (2015), começa quando a PEBT procura os canais de distribuição para a inovação, sendo que o objetivo central dessa fase é aumentar a sensibilização internacional à inovação desenvolvida. Para esses autores, nesta fase, algumas PEBTs têm o conceito de negócio já desenvolvido, incluindo estudos de viabilidade e estudos de mercado.

Figura 1 - O Processo de Comercialização - Modelo Pellikka

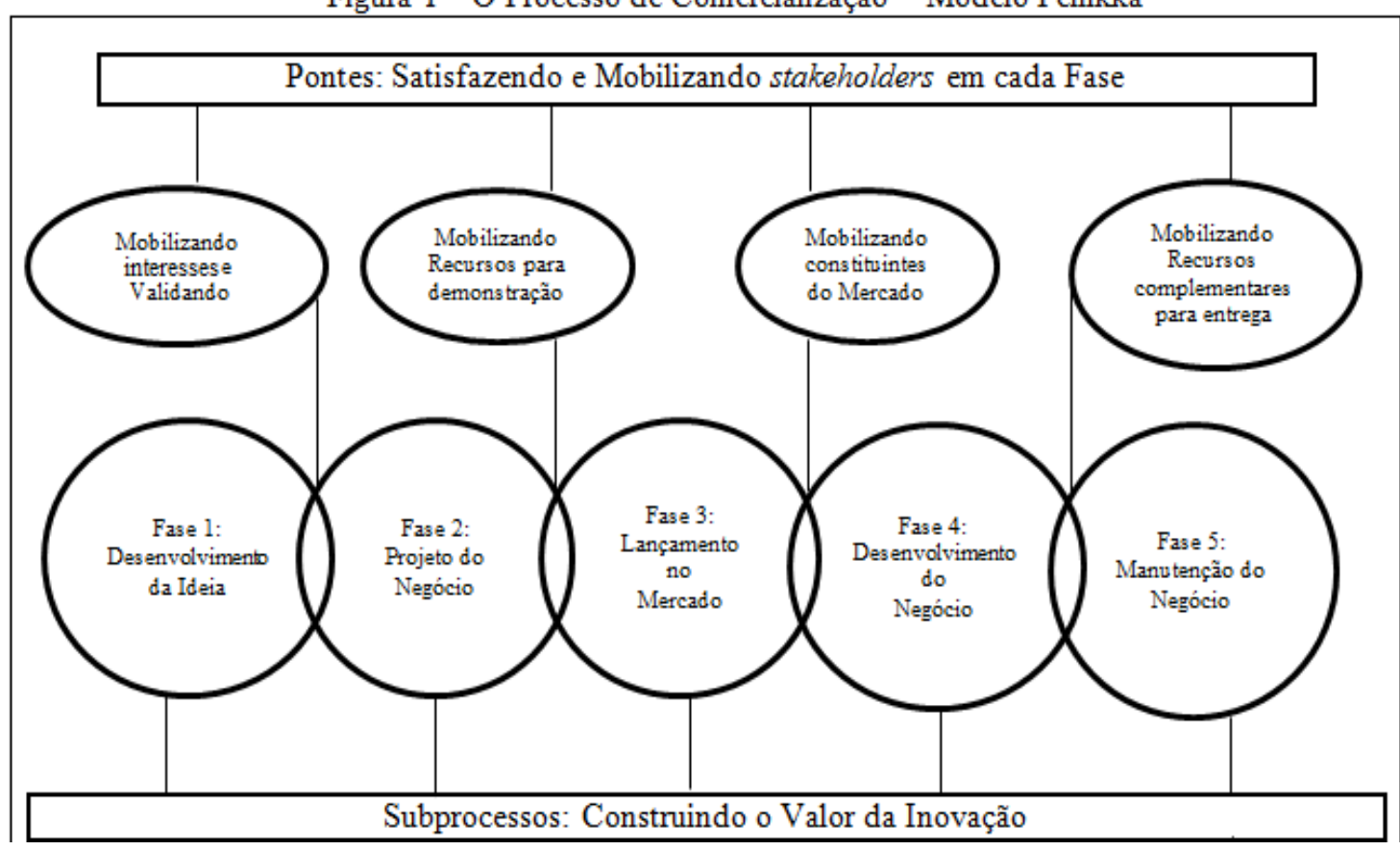




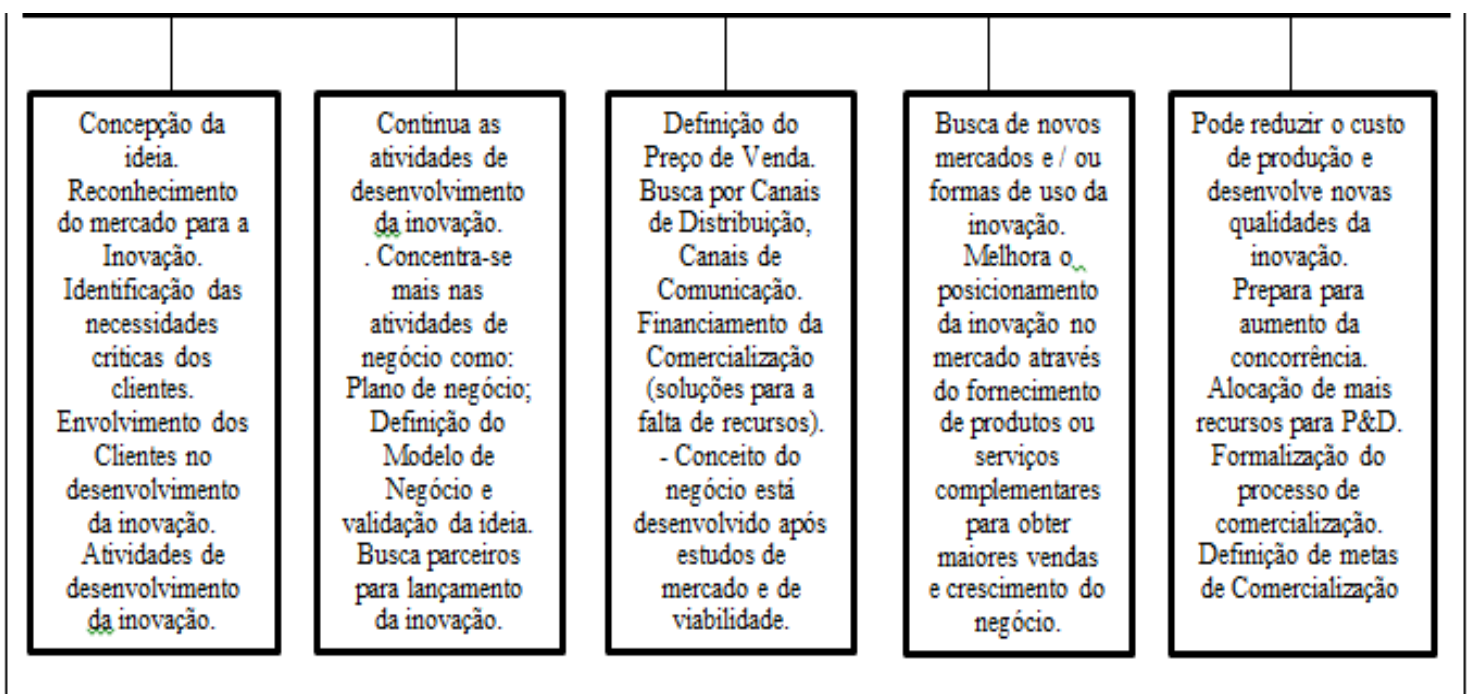

Fonte: Adaptado de Pellikka e Lauronen (2007) e Pellikka e Malinen (2015)

Para as PEBTs, as etapas mais difíceis do processo de comercialização são as "pontes", que apontam para onde os recursos precisam ser mobilizados de maneira a garantir a concretização do processo. Em todas as principais áreas problemáticas, a incapacidade em adquirir ou mobilizar tais recursos é considerada um real problema (PELLIKKA e VIRTANEN 2009).

O trabalho de Pellikka e Virtanen (2009) contribui para essa discussão ao identificar os problemas concretos que PEBTs enfrentaram durante as "pontes" do seu processo de comercialização. Os autores consideram que uma área de problema é definida como uma parte funcional do negócio ou do seu ambiente, por exemplo, marketing, finanças. Já um problema é definido como uma situação concreta nessa parte funcional ou ambiente, como por exemplo, a incapacidade de adquirir os recursos adequados para marketing (PELLIKKA e VIRTANEN, 2009) e (KAJANUS, et. al. 2011).

Segundo esses autores, estudos anteriores sugerem que as principais áreas problemáticas no processo de comercialização são (Quadro 1):

\section{Quadro 1- Áreas Problemáticas e Problemas Concretos do Processo de Comercialização}

Área

Ambiente de comercialização

Financiamento
Problema Concreto

A disponibilidade de recursos qualificados, infraestrutura adequada, a existência de serviços de apoio e desenvolvimento e redes de negócios.

O capital insuficiente, problemas de fluxo de caixa, e os problemas no controle de margens / lucros e despesas.

Desenvolvimento de competências
organizacionais e de alocação de recursos. Deixar de definir metas de comercialização, falta de colaboração e parcerias para 
comercializar P\&D e a falta de explorar as oportunidades de mercado de forma rápida.

Aquisição de informações de mercado (as

Marketing empresas não conseguem entender o potencial de mercado real e as necessidades de seu mercado e clientes).

Fonte: Adaptado de Pellikka e Virtanen (2009) e Kajanus et. al. (2011).

Observa-se no Quadro 1 que os principais problemas de comercialização enfrentados pelas PEBTs encontram-se nas áreas de gestão e marketing.

Freel (2005) também dá destaque sobre a aptidão das pequenas empresas para a inovação e aponta consistentemente para a onipresença das habilidades de gestão insuficientes $\mathrm{e}$, mais precisamente, as habilidades de marketing insuficientes. Para esse autor, as deficiências de gestão dentro das pequenas empresas incluem entre outras coisas: (1) uma má avaliação do planeamento financeira (que conduz a uma subestimação sistemática dos custos de comercialização e de desenvolvimento do produto); (2) delegação inadequada; (3) falta de experiência e / ou apoio funcional; (3) descontinuidade do pessoal de gestão; (4) esforços de marketing insuficientes e (5) dependência de vendas ad hoc ou boca-a-boca.

Modelos de processo de comercialização formalizados têm se mostrado ferramentas eficazes para minimizar as limitações apontadas acima. Para Pellikka e Pellikka (2011), o uso de modelo mais formal têm ajudado as PEBTs a superar alguns dos desafios associados à comercialização, pois essas empresas passam a ter uma percepção mais ampla do processo de comercialização e tendem a encontrar menos problemas do que as outras empresas que não utilizam tal modelo (PELLIKKA e PELLIKKA, 2011).

Segundo Pellikka e Pellikka (2011), o uso de um modelo como suporte e orientação para a comercialização tem ajudado as PEBTs a: (1) identificar as principais atividades necessárias para o processo; (2) garantir que estas atividades essenciais sejam realizadas de forma eficiente; (3) definir objetivos mensuráveis (por exemplo, custo, cronograma e recursos); (4) planejar e coordenar a colaboração com várias organizações externas (por exemplo, prestadores de serviços de apoio à inovação) e (5) obter recursos e ativos complementares que contribuem para as demais fases do processo de comercialização.

Por outro lado, o trabalho de Mazzarol, Reboud e Soutar (2011) sugere que o crescimento das vendas em PEBTs é potencialmente sem relação com qualquer atividade de formal dentro das empresas estudas, incluindo avaliações formais de mercado.

\section{Metodologia}

Devido às características da pesquisa e à busca de um entendimento aprofundado e detalhado do Processo de comercialização de inovações por uma PEBT graduada, bem como da identificação das dificuldades enfrentas por essa empresa neste processo e de quais soluções ela aplicou para superá-las, optou-se por fazer uma pesquisa exploratório-descritiva, com uma abordagem metodológica qualitativa, na qual se buscou a identificação e explicação sistemática

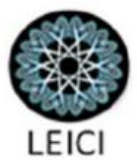


de fatos que ocorrem num contexto social, geralmente relacionado a uma multiplicidade de variáveis (GIL, 2006).

Para analisar os fatos do ponto de vista empírico optou-se pelo método estudo de caso que, segundo Yin (2010), significa fazer uma pesquisa empírica visando investigar um fenômeno contemporâneo dentro do seu contexto real, de forma especial quando os limites entre o fenômeno e o contexto não estão claramente definidos. Para esse autore, a descoberta do "como" e do "por que" determinam o que se deseja responder na pesquisa.

Este estudo analisou uma PEBT graduada na Incubadora de Base Tecnológica da Universidade Federal de Viçosa - IBT/CENTEV.

As entrevistas foram realizadas com três dos quatro sócios da empresa (sócio quotista pesquisador S1, sócia gerente S2 e sócia quotista pesquisadora S3). A primeira ocorreu em setembro de 2015 com um dos sócios fundadores - S1 (quem promoveu a criação da empresa). Ele é professor e pesquisador do Departamento de Solos da UFV (aposentando desde 2008, atuando, no entanto, como voluntário). A segunda entrevista foi com a outra sócia pesquisadora, em outubro de 2016, e a validação dos resultados foi com a sócia gerente (que está na empresa desde 2013) também em outubro de 2016. Por questões de sigilo, a empresa objeto desta pesquisa foi denominada de Empresa 11 - E11.

\section{A Organização em Estudo}

A Empresa 11 iniciou suas atividades em 2007, passando por um período de incubação de quatro anos. Atua na área de Nutrição Vegetal, desenvolvendo adubos específicos para orquídeas e plantas ornamentais e oferecendo aos produtores fertilizantes que contêm, de forma equilibrada, todos os nutrientes para produção de belas e grandes flores.

Os produtos foram desenvolvidos e testados por pesquisadores e engenheiros agrônomos com amplo conhecimento em solos e nutrição de plantas. "Nosso produto é de domínio de conhecimento, mas o empresário não apareceu em mim...eu me dedico mais à publicação de artigos e trabalhos do que a empresa" (Entrevistada S1, 2015).

Dentre os principais produtos, serviços e soluções oferecidas pela empresa, destacamse fertilizantes minerais para Orquídeas, Rosas, Bromélias e Violetas; fertilizante organomineral para flores em geral e meio de cultura para germinação in vitro de sementes de orquídeas.

Atualmente, possui quatro sócios e dois funcionários. Dos quatro sócios, dois são quotistas (um deles professores e pesquisador na UFV) e dois trabalham no negócio.

O valor total da folha de pagamento da empresa é de $\mathrm{R} \$ 3.500,00$ e é baseada em salários. Cabe notar que o faturamento total de 2010 a 2015 (72 meses) foi de $\mathrm{R} \$ 361.032,00$, o que representa uma média mensal de pouco mais de $\mathrm{R} \$ 5.000$, conforme apresentado no gráfico 1 .

Gráfico 1: Faturamento total de 2010 a 2015 


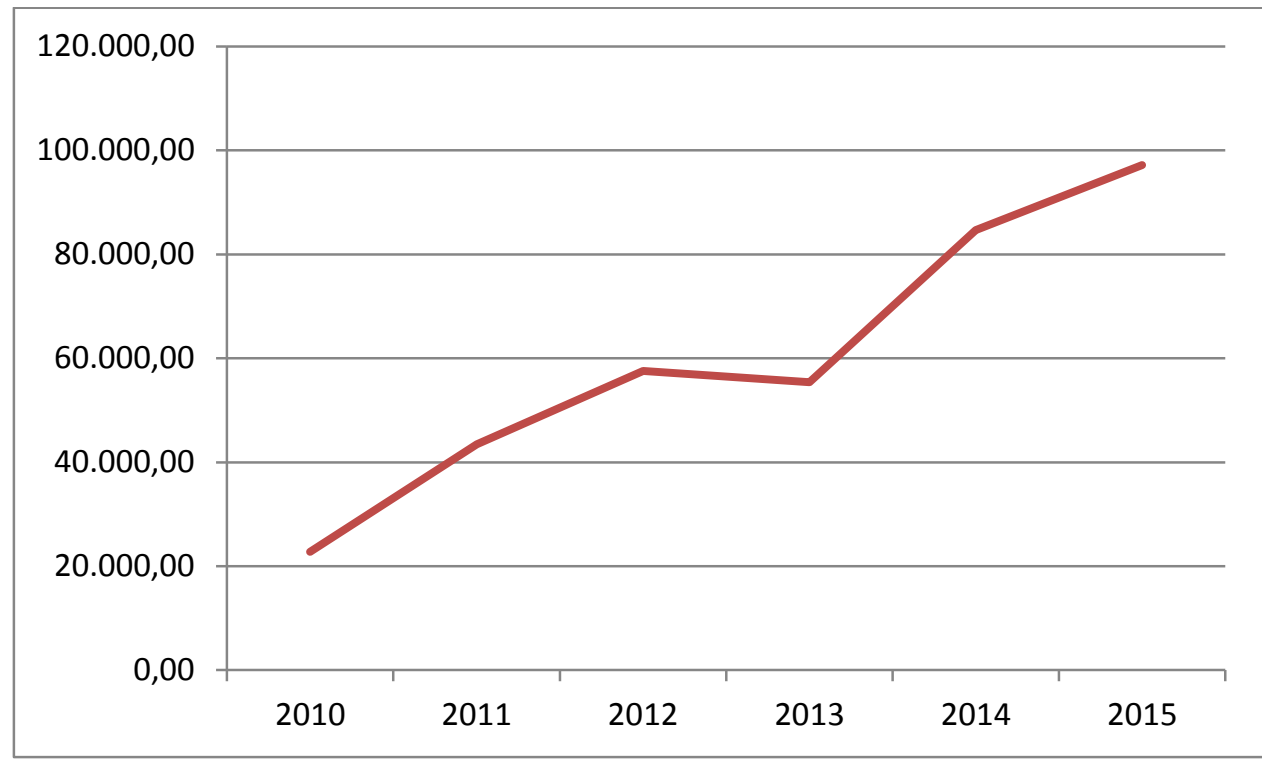

Fonte: Dados da pesquisa (2015).

Nesse período apresentado, a E11 apresentou um crescimento médio anual de 37,40\% no faturamento. Apesar disso, o volume de vendas pode ser considerado muito baixo em comparação às outras PEBTs graduadas no Brasil e em Minas Gerais (ANPROTEC, 2012; FARIA, 2015). O faturamento em 2015 foi de, aproximadamente, $\mathrm{R} \$ 97.159,00,13 \%$ superior ao de 2014. O entrevistado afirmou que o faturamento estava estagnado em 2015.

O capital inicial da empresa foi de $\mathrm{R} \$ 40.000,00$ e o sócio entrevistado acredita que já tinham sido investidos um montante de R \$100.000,00 no negócio, destinado a melhorias nos processos de produção.

Os sócios entraram com um pedido de patente, mas ele foi retirado pelo sócio entrevistado, que alegou inadequação da solicitação.

Dentre as entidades que deram apoio, foram citadas a incubadora e o SEBRAE-MG. Já ao longo da existência da empresa, a UFV e a FAPEMIG, por meio de projetos de pesquisa para o desenvolvimento do produto, criaram um orquidário na universidade para servir de laboratório.

Dois dos sócios têm doutorado, um mestrado e o quarto possui graduação, todos na área de Engenharia Agronômica. Interessante notar que nenhum dos sócios tinha experiência em negócios antes de abrir a empresa. Para o entrevistado, fez falta alguém com "espírito empresarial" atuando na empresa e, por isso, procurava algum aluno com esse espírito, o que não é fácil. "É preciso pensar em dinheiro pelo menos uma hora por dia".

O primeiro entrevistado (S1) acredita que se tivesse alguém com visão empresarial o negócio teria crescido muito, porque o produto é bom e diferenciado: "recebi um e-mail da coordenadora do IBAMA de Brasília dizendo que nosso produto é o melhor que ela já conheceu até hoje". Para a sócia gerente (S2), 
esse é o nosso problema até hoje, ninguém tem visão de negócio...eu também sou pesquisadora e aí a gente tem que dar conta de tudo, estou procurando fazer cursos com o SEBRAE para melhorar essa parte.

Temos um produto muito bom, mas não estamos sabendo trabalhar isso no mercado, tanto que ele está indo no boca-a-boca...tem anos que a empresa está sempre no mesmo ponto...agora que eu te falo que a empresa está dando uma alavancada muito boa, coisa que nunca aconteceu, de chegar o começo do mês e eu ter dinheiro na conta.

A partir do início de 2016 comecei a investir um pouquinho mais em divulgação, facebook, e-mail marketing...além disso, mudamos o produto de forma sólida para forma líquida, a partir do começo de 2015...mas ainda temos muito mercado para expandir e temos que expandir para ter lucro, pois a empresa ainda não deu lucro, apenas pagou seus custos.

O sócio pesquisador (S1) considerava que a empresa precisava ganhar escala na produção, aumentar o número de clientes e faturar mais, uma vez que sabia que o produto oferecido tem mercado. Segundo ele, "precisamos parar um pouco com as pesquisas e ter um marketing mais agressivo, mas eu não tenho o espírito empresarial, porque se tivesse a empresa estaria em outro patamar...está faltando motor para a empresa e eu sou culpado disso".

A sócia gerente (S2) afirmou que a empresa não chegou a lançar o produto no mercado, pois as primeiras vendas foram muito pontuais, com pessoas que trabalhavam com orquídeas na cidade, conhecidas dos fundadores: "vendia para um amigo aqui, outro amigo ali". As indicações desses primeiros clientes foi o que fortaleceu a empresa e hoje ainda continua o boca a boca, inclusive em grupos de whatsapp: "eu recebo mensagens dizendo que estão divulgando a empresa em outros grupos e que membros desses grupos querem comprar o produto...o contato com a UFV também ajuda muito, tem gente que liga querendo comprar o adubo da UFV".

A sócia pesquisadora (S3) também destacou como conseguiram os primeiros clientes, afirmando que "as primeiras vendas foram feitas para amigos orquidófilos (Associação Orquidófila e Orquidóloga de Viçosa - AOOV) e conhecidos orquidófilos da região e amigos conhecidos". No início, disse que eles comentaram com os amigos a respeito do adubo e, com a produção dos primeiros produtos, faziam divulgação para seus conhecidos, que passavam a procurar a E11. Isso evidencia a ativação da rede de contato dos empreendedores e a importância da divulgação por meio da indicação boca a boca.

Percebe-se que, apesar do entrevistado (S1) estar aposentando desde 2008, ele ainda continuava atuando como professor e pesquisador, inclusive orientando alunos na pós-graduação e integrando aa Sociedade Brasileira de Ciência do Solo. Disse que questões burocráticas, como autorizações de órgãos fiscalizadores, foram umas das principais dificuldades enfrentadas pela E11, pois isso atrasou o funcionamento da empresa e o início da produção e venda, o que foi confirmado pelos três entrevistados. Até hoje, destaca-se, o entrevistado não teve nenhuma remuneração da empresa, nem como retirada, nem como lucros distribuídos.

O faturamento geralmente cobre os custos e despesas da empresa e foram raras as vezes em que ele precisou desembolsar dinheiro para os gastos do mês. Tudo que produzem é

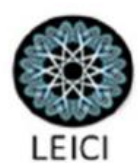


vendido, especialmente porque o diferencial do produto está no ajuste da dosagem e equilíbrio de nutrientes do adubo (Belas e Grandes Flores - B\&G Flores).

As vendas não acontecem em grandes volumes, porque não há nenhuma prática de comercialização estruturada, o que faz falta para a empresa. Além das vendas pela loja própria (que gira em torna de R \$100,00/dia), há algumas vendas pontuais (como para o supermercado Escola da UFV) e pela internet, via site. Segundo a sócia gerente (S2), elas não crescem devido à falta de iniciativas para ampliar parceiras e pontos de venda.

Quase não temos venda na loja, nosso forte é venda pela internet e pontos de revenda em alguns estados no Brasil...esses pontos de revenda (que hoje somam cerca de 40) é que nos procuram, nós não temos tempo de procurar outros pontos de revenda pelo país, em todos os casos eles que nos procuraram...até hoje eu nunca fiz contato com nenhum.. esse número poderia estar muito maior, pois temos capacidade produtiva para isso.

Segundo o primeiro entrevistado (S1), isso ainda não foi resolvido por falta de iniciativa dos sócios, que não possuem o "espírito empreendedor". "Se você não tem mercado, você não tem empresa...o mercado de floricultura está em crescendo e com ele o de insumos, por isso temos como crescer...a parte de desenvolvimento do produto está indo bem".

O que fazem é colocar anúncios em algumas revistas especializadas e divulgar o produto em congressos especializados na área de orquídeas, além de usar o site e redes sociais, o que passaram a fazer com mais frequência a partir de fevereiro de 2015. "Tem um aluno na pósgraduação que é da Argentina que está levando nosso produto para lá e quer se tornar nosso representante" (Entrevistado Sócio Pesquisador, 2015). Não possuíam nenhum canal de distribuição e nenhum representante comercial até há três anos.

O sócio pesquisador ( $\mathrm{S} 1$ ) considera que o Brasil tem mercado para floricultura, apesar de as pessoas ainda não terem o hábito e a cultura de presentear outras pessoas com flores. Por isso, acredita que a empresa tem como crescer muito, pois tem e terá mercado para isso.

Questionada sobre a influência do período de incubação no processo de comercialização, a sócia quotista (S3) afirmou que a IBT/UFV sempre esteve muito próxima da E11, passando informações e indicações de onde e como conseguir soluções para as dificuldades iniciais, inclusive indicando clientes potenciais. $\mathrm{O}$ fato de estar na incubadora foi considerado de grande importância para a entrevistada.

O Quadro 2 a seguir apresenta de forma detalhada as evidências encontradas na E11 em cada fase do processo de comercialização.

\section{Quadro 2: Processo de comercialização de inovações da Empresa 11}

\begin{tabular}{|l|l|}
\hline & $\begin{array}{l}\text { A partir de uma parceria com outro professor que também trabalhava } \\
\text { com orquídeas (ambos como hobby), começaram a perceber a } \\
\text { carência de cálcio em suas plantas, momento que começaram a tratá- }\end{array}$ \\
$\begin{array}{l}\text { Fase de desenvolvimento } \\
\text { las com nitrato de cálcio, só encontrando, no entanto, sacos de 50 } \\
\text { da Ideia }\end{array}$ & $\begin{array}{l}\text { quilos. Os dois demoraram 15 anos para desenvolver a pesquisa e } \\
\text { testar o fertilizante. Por meio da modelagem, começaram a testar e } \\
\text { aplicar as dosagens corretas de nutrientes para vários tipos de }\end{array}$ \\
\hline
\end{tabular}




\begin{tabular}{|c|c|}
\hline & $\begin{array}{l}\text { orquídeas. Os produtos foram desenvolvidos e testados por } \\
\text { pesquisadores e engenheiros agrônomos com amplo conhecimento } \\
\text { em solos e nutrição de plantas. "Nosso produto é de domínio de } \\
\text { conhecimento, mas o empresário não apareceu em mim...eu me } \\
\text { dedico mais à publicação de artigos e trabalhos do que a empresa". }\end{array}$ \\
\hline $\begin{array}{l}\text { Fase do Projeto } \\
\text { do Negócio }\end{array}$ & $\begin{array}{l}\text { A empresa iniciou suas atividades em 1998, passando por um período } \\
\text { de incubação de dois anos. Atua na área de Nutrição Vegetal, } \\
\text { desenvolvendo adubos específicos para orquídeas e plantas } \\
\text { ornamentais, oferecendo aos produtores fertilizantes que contêm, de } \\
\text { forma equilibrada, todos os nutrientes para produção de belas e } \\
\text { grandes flores. }\end{array}$ \\
\hline $\begin{array}{ll}\text { Fase } & \text { de } \\
\text { Lançamento } & \text { no } \\
\text { Mercado } & \end{array}$ & $\begin{array}{l}\text { Nenhum dos sócios possuía experiência em negócios antes de abrir a } \\
\text { empresa e o entrevistado considera que faz falta alguém com "espírito } \\
\text { empresarial" atuando na empresa e que procura por algum aluno com } \\
\text { esse espírito, mas não é fácil. "É preciso pensar em dinheiro pelo } \\
\text { menos uma hora por dia". Ele acredita que se tivesse alguém com a } \\
\text { visão empresarial o negócio teria crescido muito, porque o produto é } \\
\text { bom e diferenciado. Segundo ele, "recebi um e-mail da coordenadora } \\
\text { do IBAMA de Brasília dizendo que nosso produto é o melhor que ela } \\
\text { já conheceu até hoje". }\end{array}$ \\
\hline $\begin{array}{l}\text { Fase de } \\
\text { Desenvolvimento } \\
\text { do Negócio }\end{array}$ & $\begin{array}{l}\text { As vendas não acontecem em grandes volumes, não possuem } \\
\text { nenhuma prática de comercialização estruturada e o entrevistado } \\
\text { considera que isso está fazendo falta para a empresa. Existem } \\
\text { algumas vendas pontuais (supermercado Escola da UFV) e pela } \\
\text { internet, via site da empresa. Ele considera que a empresa precisa } \\
\text { ganhar escala na produção, aumentar o número de clientes e faturar } \\
\text { mais, pois acredita que o produto tem mercado. Segundo ele, } \\
\text { "precisamos parar um pouco com as pesquisas e ter um marketing } \\
\text { mais agressivo, mas eu não tenho o espírito empresarial, porque se } \\
\text { tivesse a empresa estaria em outro patamar...está faltando motor para } \\
\text { a empresa e eu sou culpado disso". Segundo ele, isso ainda não foi } \\
\text { resolvido por falta de iniciativa dos sócios, que não têm o "espírito } \\
\text { empreendedor". "Se você não tem mercado, você não tem } \\
\text { empresa...o mercado de floricultura está em crescendo e com ele o de } \\
\text { insumos, por isso temos como crescer...a parte de desenvolvimento } \\
\text { do produto está indo bem". }\end{array}$ \\
\hline
\end{tabular}




\begin{tabular}{|l|ll}
\hline Fase & de \\
Manutenção do & do & $\begin{array}{l}\text { O faturamento em } 2014 \text { foi de, aproximadamente, } \mathrm{R} \$ 60.000,00, \text { uma } \\
\text { média mensal de pouco mais de } \mathrm{R} \$ 5.000,00 . \text { O entrevistado acredita } \\
\text { que, no momento da entrevista, o faturamento estava estagnado. Até } \\
\text { hoje o entrevistado não teve nenhuma remuneração da empresa, nem } \\
\text { como retirada, nem como lucros distribuídos. No entanto, declarou } \\
\text { que desde o início das atividades, foram raras as vezes que precisou } \\
\text { desembolsar algum dinheiro para manter o negócio. }\end{array}$ \\
\hline
\end{tabular}

Fonte: Dados das pesquisas (2015).

\section{Análise e Discussão do Estudo de Caso}

A E11 apresentou um crescimento médio anual de 37,4\% no faturamento de 2010 a 2015. O faturamento total nesse período ( 72 meses) foi de $\mathrm{R} \$ 361.032,00$, o que representa uma média mensal de pouco mais de $\mathrm{R} \$ 5.000,00$, valor muito inferior à média das PEBTs graduadas do Brasil em 2011 (R\$ 133.000,00) e à média mensal das PEBTs graduadas em Minas Gerais em $2013(\mathrm{R} \$ 120.000,00)$.

No mesmo período, a empresa manteve o número de pessoas ocupadas em seis, sendo quatro sócios e dois funcionários.

Apesar de ter apresentado um crescimento no faturamento, o valor das vendas pode ser considerado muito baixo em comparação às outras PEBTs graduadas. Em seus nove anos de existência, observou-se que a empresa não conseguiu alavancar esse faturamento e crescer em vendas e número de empregados. Destaca-se a seguir algumas evidências que podem explicar esse desempenho:

Pode-se considerar que a E11 não chegou a lançar seu produto no mercado efetivamente, pois as primeiras vendas foram feitas para pessoas da cidade, em situações pontuais. Elas trabalhavam com orquídeas em Viçosa e eram conhecidas dos fundadores.

Observou-se que não existe um modelo de negócio definido na empresa, que praticamente faz suas vendas de forma passiva, ou seja, à medida que é procurada pelos pontos de revenda ou por algum cliente diretamente, principalmente via internet.

Mesmo após esses anos de existência, poucas vendas acontecem na loja física. A principal maneira de vender é pela internet e em pontos de revenda em alguns estados no Brasil.

Não foi possível identificar um modelo formalizado/estruturado do processo de comercialização da E11. Tais atividades se davam mais por demanda de alguns clientes de forma esporádica e isolada e menos por estratégias e ações dos empreendedores. Os trabalhos de Pellikka e Pellikka (2011) e Hang Do (2014) divergem dos achados de Mazzarol, Reboud e Soutar (2011) e evidenciam que as PEBTs que utilizam um modelo de processo de comercialização mais formalizado encontraram menos problemas e tiveram uma percepção mais ampla do processo de comercialização.

Em 2016, após uma consultoria que teve como finalidade melhorar o site, iniciaram algumas ações de marketing digital, utilizando redes sociais e e-mail marketing e, a partir daí, perceberam que o faturamento começou a crescer. Foram os pontos de revenda existentes que procuraram a empresa e não existe nenhuma ação de prospecção de novos canais de revenda como os existentes.

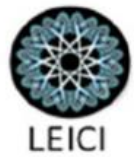


Observou-se que os empreendedores têm uma rede de contato com outros pesquisadores e colecionadores de orquídeas e procuraram fazer parcerias com os pontos de revenda. No entanto, percebe-se que não ativaram ou ampliaram efetivamente esse tipo de rede e de parceria.

Os empreendedores possuem limitadas competências em gestão e comercialização, o que pode ser explicado pelo fato de os sócios terem um perfil mais acadêmico, com pouca expertise na condução de um negócio, apesar do tempo de existência da E11. Os trabalhos de Datta, Red e Jessup (2013), Pellikka e Virtanen (2009), Freel (2005), Forsman (2011), Pellikka e Malinen (2014 e 2015), de Jong e Marsili (2006) e Liao e Rice (2010) destacaram a importância das PEBTs terem tais capacidades e competências e o papel do treinamento e da formação para os empreendedores das PEBTs adquirirem tais capacidades e competências.

\section{Conclusões}

Nesse estudo procurou-se respostas para as seguintes perguntas: (1) Como é o processo de comercialização de inovações de uma PEBT graduada? (2) Quais as dificuldades a empresa enfrenta nesse processo? (3) Como supera essas dificuldades para introduzir suas inovações no mercado? 4) O período de incubação tem alguma influência na comercialização?

Pode-se considerar que a Empresa 11 ainda não entrou na Fase de Lançamento no Mercado e que um dos principais problemas evidenciados no estudo está na base de competências em gestão e comercialização por parte dos sócios, pois a empresa foi criada por empreendedores técnicos (empreendedor acadêmico) com uma forte orientação tecnológica e fraca orientação mercadológica e empresarial.

Outro problema refere-se à escassez de recursos financeiro do empreendimento e precisa ser resolvido, pois é necessário investir durante um longo período em pesquisa e esperar por resultados de comercialização de longo prazo. A ausência de recursos financeiros é um obstáculo à realização das atividades de comercialização e à contratação de recursos humanos com experiência, e, consequentemente limita o crescimento das vendas.

Uma prática que passou a ser desenvolvida pela empresa em 2016 e que começou a impactar positivamente no faturamento e minimizar os problemas de comercialização foi o uso ferramentas de marketing digital (internet, e-mail marketing, Google, redes sociais).

Cabe destacar que essas soluções não requerem recursos financeiros elevados e os resultados desse estudo apontam para sua efetividade.

Apesar dos empreendedores entrevistados considerarem que o período de incubação foi importante para a empresa, não foi possível identificar influência direta da incubadora no processo de comercialização.

Agradecimentos: Os autores agradecem à CAPES - Coordenação de Aperfeiçoamento de Pessoal de Nível Superior, fundação do Ministério da Educação (MEC) e ao Centro Federal de Educação Tecnológica - CEFET-MG, pelo apoio concedido para a realização dessa pesquisa.

\section{REFERÊNCIAS BIBLIOGRÁFICAS}
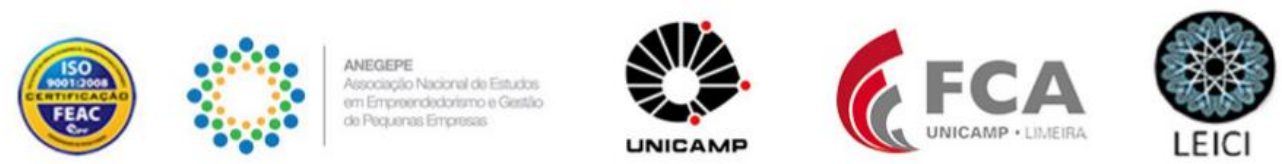
ADAMS, R., BESSANT, J., AND PHELPS, R. (2006). "Innovation Management Measurement: A Review." International Journal of Management Reviews 8(1): 21-47.

ANDRADE JUNIOR, Pedro Paulo de.; The Brazilian Experience In Overcoming Difficulties of Technology-Based Companies in Incubators. Journal of Technology Management \& Innovation, v. 7, p. 161-171, 2012.

ANPROTEC, Estudo, Análise e Proposições sobre as Incubadoras de Empresas no Brasil - relatório técnico / Associação Nacional de Entidades Promotoras de Empreendimentos Inovadores. Ministério da Ciência, Tecnologia e Inovação. - Brasília: ANPROTEC, 2012.

DE JONG, J.; MARSILI, O. The fruit flies of innovations: A taxonomy of innovative small firms. Research Policy 35 (2006) 213-229

FARIA, Adriana Ferreira de. Estudo, análise e proposições sobre as incubadoras de empresas de Minas Gerais / Adriana Ferreira de Faria, Marcos Fernandes de Castro Rodrigues, Wagner Rogério Ferreira Pinheiro. - Viçosa, MG : Centev, 2015. 124 p. : il. (algumas color.) ISBN: 978-85-65798-01-3

FORSMAN, H. Innovation capacity and innovation development in small enterprises. A comparison between the manufacturing and service sectors. Research Policy 40 (2011) 739-750

EISENHARDT, K. M.; GRAEBNER, M. E. (2007). Theory building from cases: Opportunities and challenges. Academy of Management Journal, 50, 1: 25-32.

FREEL, M S. Patterns of innovation and skills in small firms. Technovation 25 (2005) 123-134

GIL, A. C. Métodos e Técnicas de Pesquisa Social. 5.ed. São Paulo: Atlas, 2006.

HANG DO, Thuy. Determinants of Innovation Commercialization Management and Anticipated Returns: An Exploratory Typology of SMEs. International Journal of Innovation and Technology Management Vol. 11, No. 6 (2014) 1450042 (20 pages)

IACONO, Antônio.; NAGANO, Marcelo Seido. Gestão da Inovação em Empresas Nascentes de Base Tecnológica: Evidências em Uma Incubadora de Empresas no Brasil. Interciência (Caracas) v. 39, p. 296-306, 2014.

KAJANUS, M.; HEINOEN, M.; ESLELINEN, T.; PELLIKKA, J. Callenges in Commercialisation Processess of Product Innovation SMEs. (2011). EBRF conference (Research Forum to Understand Business in Knowledge Society) Disponível em < http://www.ebrf.fi/_file/43891/EBRF11_1005.pdf > Acesso em 19/11/14.

LIAO, T; RICE J. Innovation investments, market engagement and financial performance: A study among Australian manufacturing SMEs. Research Policy 39 (2010) 117-125

MAZZAROL, T.; REBOUD, S.; SOUTAR G. (2011) Innovation Management and Commercialisation in Small Firms: A Study of OECD Countries. 56th Annual ICSB World Conference. Disponível em <http://www.cemi.com.au/sites/all/publications/Mazzarol\%2C\%20Reboud\%20and\%20Soutar\%20ICS B\%202011.pdf> Acesso em 19/11/14.

MOORE, G. (2002). Crossing the Chasm. Harper Business, New York.

NUNES, P. M.; SERRASQUEIRO, Z.; LEITÃO, J. Is there a linear relationship between R\&D intensity and growth? Empirical evidence of non-high-tech vs. high-tech SMEs. Research Policy 41 (2012) 3653 
PELLIKKA, J.; VIRTANEN, M. Problems of commercialisation in Small Technology-Based Firms. Int. J. Entrepreneurship and Innovation Management, Vol. 9, No. 3, pp.267-284 (2009).

PELLIKKA, J.; PELLIKKA, J. Are commercialisation process models beneficial for small technology firms? Int. J. Technology Transfer and Commercialisation, Vol. 10, Nos. 3/4, pp.229-246 (2011).

PELLIKKA, J.; LAURONEN. Fostering commercialisation of innovation in small high technology firms. International Journal Technoentrepreneurship, Vol. 1, No. 1, 2007.

PELLIKKA, J.; MALINEN P. Fostering Business Growth and Commercialisation Processes in Small High Technology Firms. International Journal. Business Environment, Vol. 7, No. 1, 2015.

PELLIKKA, J.; MALINEN P. Business Models in the Commercialization Processes of Innovation Among Small High-technology Firms. International Journal of Innovation and Technology Management Vol. 11, No. 2 (2014) 1450007.

PELLIKKA, J. Commercialization Process of Innovation in Small High-Technology Firms Theoretical Review. In: Handbook Of Research On Techno-Entrepreneurship, Second Edition How Technology and Entrepreneurship are Shaping the Development of Industries and Companies François Thérin Edited by François Thérin, Curtin University Sarawak, Malaysia 2014400 pp Hardback 9781 781951811 - ebook isbn 9781781951828 (2014).

PELLIKKA, J. MALINEN, P. Developing Commercialisation of Innovation in High Technology Industries - Regional Perspective. Small Business Advancement National Center - (2011). Disponível em < http://sbaer.uca.edu/research/icsb/2011/151.pdf $>$ Acesso em 19/11/14.

TIDD, J.; BESSAND, J.; Gestão da Inovação. $5^{\circ}$ ed. Porto Alegre. Bookman, 2015.

YIN, R. K. Estudo de Caso: planejamento e métodos. Trad. Daniel Grassi. 4. ${ }^{\text {a }}$ ed. Porto Alegre: Bookman, 2010.

ZAHRA, S. A. AND NIELSEN, A. P. (2002), Sources of capabilities, integration and technology commercialization. Strategic Management Journal, 23(5), 377-398.

WONGLIMPIYARAT, J.; YUBERK, N. In support of innovation management and Roger's Innovation Diffusion theory. Government Information Quarterly 22 (2005) 411-422 